\title{
The relationships of self-efficacy, physical activity, and paid work to health-related quality of life among patients with chronic obstructive pulmonary disease (COPD)
}

\author{
This article was published in the following Dove Press journal: \\ Journal of Multidisciplinary Healthcare \\ 6 June 2014 \\ Number of times this article has been viewed
}

\author{
Randi Andenæs' \\ Signe Berit Bentsen ${ }^{2}$ \\ Kari Hvinden ${ }^{3,4}$ \\ May Solveig Fagermoen ${ }^{5,6}$ \\ Anners Lerdal ${ }^{6,7}$ \\ 'Department of Nursing, Faculty of \\ Health Science, Oslo and Akershus \\ University College of Applied \\ Sciences, Oslo, Norway; ${ }^{2}$ Department \\ of Health Studies, Faculty of Social \\ Sciences, University of Stavanger, \\ Stavanger, Norway; ${ }^{3}$ LHL Helse AS, \\ Glittreklinikken, Hakadal, Norway; \\ ${ }^{4}$ Norwegian Advisory Unit for \\ Learning and Mastery in Health, Oslo \\ University Hospital, Oslo, Norway; \\ ${ }^{5}$ Department of Gastroenterology, \\ Oslo University Hospital, Oslo, \\ Norway; ${ }^{6}$ Department of Nursing \\ Science, Institute of Health and \\ Society, Faculty of Medicine, \\ University of Oslo, Oslo, Norway; \\ ${ }^{7}$ Department of Research, Lovisenberg \\ Diakonale Hospital, Oslo, Norway
}

Purpose: Although chronic obstructive pulmonary disease (COPD) primarily affects the lungs, it is regarded as a systemic disorder associated with comorbidity and physical deterioration, which often results in reduced levels of health-related quality of life (HRQoL). Self-efficacy is an important concept in self-management, which is vital for improving HRQoL in patients with COPD. The purpose of this study was to examine how general self-efficacy, leisure time physical activity, and sociodemographic variables such as employment status are related to the physical and mental health components of HRQoL in patients with COPD.

Patients and methods: In this cross-sectional study, 97 COPD patients (54.6\% male, mean age 64.6 years, standard deviation [SD] 9.5) beginning a pulmonary rehabilitation program completed three self-report questionnaires: the short form (SF)-12v2 Health Survey as a measure of HRQoL; the General Self-Efficacy Scale; and a standardized instrument measuring regular leisure time physical activity.

Results: The physical health component median score was 31.3 (interquartile range [IQR] 16.3) and the mental health component median score was 45.9 (IQR 21.5). Two sets of linear regression analyses were performed, one predicting physical health and the other predicting mental health. The first analysis showed that better physical health was directly related to being in paid work $(P$-value $<0.001)$, but was not significantly related to age, sex, marital status, education, work status, physical activity, or self-efficacy. In the second analysis, better mental health was directly related to living with a partner, being physically active, and having higher self-efficacy ( $P$-value $<0.001)$.

Conclusion: The findings suggest that general self-efficacy has differential relationships to the two dimensions of HRQoL. Our results indicate that general self-efficacy, physical activity, and paid work might be important factors for improving HRQoL of persons with COPD, and should be taken into consideration in pulmonary rehabilitation.

Keywords: chronic disease, employment, lung, rehabilitation, self-care

\section{Introduction}

According to estimates of the World Health Organization, 65 million people have moderate to severe chronic obstructive pulmonary disease (COPD). ${ }^{1}$ In 2002, COPD was the fifth leading cause of death, and it is estimated that by 2030 it will become the third leading cause of death, worldwide. ${ }^{1}$ Although COPD primarily affects the lungs, it is regarded as a systemic disorder associated with cardiovascular diseases, muscle wasting, and bone loss. ${ }^{2,3}$ As a result of these changes and even with optimal medical treatment, COPD often results in reduced levels of health-related quality of life
Correspondence: Randi Andenæs Oslo and Akershus University College of Applied Sciences, Faculty of Health Science, Department of Nursing, Postbox 4 St Olavs plass, N-0130 Oslo, Norway Tel +479289296I

Email randi.andenas@hioa.no 
(HRQoL). ${ }^{3-5}$ HRQoL is an established concept in the health sciences, describing aspects of an individual's subjective evaluation of their health, disease, disability, impairment, and the effectiveness of treatment.,

As a supplement to pharmacological therapy, pulmonary rehabilitation (PR) has emerged as a standard of care for patients with COPD. ${ }^{8}$ In Norway, at a minimum, PR programs include physical training, education, and psychosocial support. Although all PR programs include these components, they may vary considerably in their extent and structure. The principal goals of PR are to reduce symptoms, improve HRQoL, and increase physical and emotional participation in everyday activities. ${ }^{9,10}$ Physical training and self-efficacy are core components of PR programs available for COPD patients with lower HRQoL. ${ }^{8,9}$ Physical training may help to reduce muscle deconditioning, which occurs when physical activity is restricted by breathlessness and fatigue, and thus lead to better HRQoL. ${ }^{9,11}$ Many COPD patients are advised to do daily exercises (eg, walking 20 minutes daily), and observational studies indicate that leisure time physical activity has significant benefits, such as reduced hospital admissions and mortality ${ }^{12}$ and better HRQoL among patients with COPD. ${ }^{13}$

Self-management is the individual's ability to manage symptoms, treatment, physical and psychosocial consequences, and lifestyle changes when living with a chronic condition. ${ }^{14}$ Self-efficacy is an important construct in selfmanagement ${ }^{9}$ and refers to the confidence people have in their ability to perform actions that are required to deal with particular situations. ${ }^{15}$ Self-efficacy is distinct from true or actual capability, but seems to guide health behavior and control disease, resulting in better HRQoL. ${ }^{9,15,16}$ Many COPD patients seem to lose their sense of control over the disease and their lives, which may lead to lower self-efficacy. ${ }^{16,17}$ Hence, the expectations COPD patients have for their own self-efficacy are important as they can affect their success in self-management. ${ }^{16}$ Previous studies have found that, among COPD patients waiting to begin a PR program, those who had higher levels of disease-specific self-efficacy reported better physical, psychological, and social function as well as total health compared with those who had lower levels of self-efficacy. ${ }^{18,19}$

Although several studies have evaluated HRQoL in patients with COPD, health professionals need to understand the factors that potentially influence HRQoL in persons with COPD in order to better meet the needs of this population. To the authors' knowledge, no previous studies have evaluated the importance of general self-efficacy for HRQoL among patients with COPD. Thus, the aim of the present study was to evaluate the relationships among physical activity, general self-efficacy, and the physical and mental components of HRQoL, while controlling for selected demographic variables such as age, education, cohabitation, and employment status, in a sample of COPD patients at the start of a PR program.

\section{Material and methods}

A prospective longitudinal study was designed to explore whether participation in a patient educational course for persons with COPD or obesity might contribute to changes in HRQoL, and also to examine 12 instruments assessing perception of illness and coping strategies and to evaluate their ability to detect change over time..$^{20}$ This article reports findings from a cross-sectional correlational analysis of HRQoL, physical activity, self-efficacy, and socio-demographic factors among participants with COPD.

\section{Sampling and procedure}

In this convenience sample, patients were recruited in 2009-2010 at six different pulmonary rehabilitation programs in Southern Norway. All 127 participants attending the courses were given verbal and written information about the study and asked to participate on the first day of the PR course. The only inclusion criterion was course attendance. Those who gave their written consent completed the questionnaires and demographic information in a secluded room on-site, and returned the information in a sealed envelope the same day. The project representative collected the envelopes.

Of the 127 individuals asked to participate in the study, $100(78.7 \%)$ consented and 97 persons (97.0\%) had complete scores and were included in the analysis. The course participants included in the analysis $(n=97)$ did not differ with respect to age $(P=0.24)$ or sex $(P=0.30)$ from those who were excluded due to incomplete scores or who did not consent $(n=30)$.

\section{Measurements}

HRQoL was measured with the short form (SF)-12 Health Survey, version 2 (SF-12v2) with 1-week recall. The 12-item version is a widely used abbreviated questionnaire derived from the Medical Outcomes Study SF-36 instrument and measures eight domains of physical functioning, role limitations due to physical health, bodily pain, general health perceptions, vitality, social functioning, role limitations due to emotional problems, and mental health. ${ }^{21,22}$ The raw scores on the eight scales are converted to standard scores from 0 (lowest HRQoL) to 100 (highest HRQoL). A physical component summary (PCS) and a mental component 
summary (MCS) score were computed, reflecting underlying physical and mental dimensions of HRQoL, respectively. ${ }^{21}$ Norm-based standardized scores, based on the 1998 general US population, ${ }^{21}$ were computed for all eight scales. Missing items were replaced with the mean of the other items in the same scale. The SF-12 has been validated for use in the USA, UK, and many other European countries. ${ }^{23}$ The SF-12 has shown excellent measurement properties in COPD populations. $^{24}$

Level of physical activity (PA) was measured by two items from the Norwegian Nord-Trøndelag Health Survey (HUNT study), assessing frequency and intensity of leisure activities. ${ }^{25}$ In response to the question "How much physical activity do you have during leisure time?", participants were asked to state approximately how many hours per week they performed; either: 1) low-level physical activity (not becoming sweaty/breathless); and/or 2) high-level activity (becoming sweaty/breathless). Response alternatives were "no activity", "less than 1 hour", "1 to 2 hours", and "3 or more hours a week". An index score ranging from 0-3 was computed in accordance with the current published categorization. ${ }^{25}$ The PA questions from HUNT have been used in a number of studies assessing the possible effects of PA on different health outcomes, including mortality, stroke, diabetes, weight control, risk of several types of cancer, and osteoporosis. ${ }^{26,27}$ Acceptable test-retest reliability and acceptable validity, particularly for measurement of moderate and high-intensity leisure PA, have been reported. ${ }^{26}$

Self-efficacy was assessed using the General SelfEfficacy Scale (GSE). ${ }^{28}$ The GSE is a ten-item scale designed to evaluate the beliefs that one can perform novel or difficult tasks in life or cope with hardship (eg, "I am confident that I could deal efficiently with unexpected events"). The score for each question ranges from 1 to 4 , with the anchors "completely disagree" and "completely agree". A GSE score is calculated by summing the responses to all ten items; higher scores indicate stronger self-efficacy (range from ten to 40$)$. Up to two of the responses $(20 \%)$ were allowed to be missing and were replaced with the mean value of the person's valid scores. The scale has been translated into several languages, including Norwegian, and has demonstrated good psychometric properties. ${ }^{28-30}$ In the present study, the internal reliability coefficient for the scale was 0.92 , which is considered excellent. ${ }^{6}$

Data were also collected on age (years), sex, marital status (married/cohabitating versus not married/not cohabitating), and employment status (in paid work versus not in paid work). Respondents were asked to indicate their highest formal education. Response categories were primary school education (7-9 years), 1 or 2 years of secondary school (10-11 years), 3 years of secondary school (12 years), lower university (13-15 years), and higher university ( $\geq 16$ years). Formal education was dichotomized into two categories: up to 12 years education versus more than 12 years.

\section{Ethics}

The Regional Medical Research Ethics Committee of Norway (REK S-08662c 2008/17575), and the Ombudsman of Oslo University Hospital approved the study. Informed written consent was obtained from all participants.

\section{Statistical analysis}

Normality of the data was assessed by visual inspection, and several of the HRQoL scales were not normally distributed. Independent $t$-tests (for two samples with equal or unequal variance when appropriate) were used to analyze continuous variables with normal distributions (age, physical activity, and GSE), and the non-parametric Mann-Whitney $U$ test was used for the HRQoL scales. Ordinal and categorical data were analyzed using the chi-square and the Fisher's exact tests. Pearson's correlation coefficient $(r)$ was used for correlation analysis. Descriptive statistics included mean scores with standard deviation or median scores with interquartile range. Cronbach's $\alpha$ was computed to assess the internal consistency of the scales. ${ }^{31}$

To determine the relationship between the independent variables and HRQoL, two sets of linear regression analyses were performed. The PCS score was used as the dependent variable in the first set of analyses and the MCS score as the dependent variable in the second. First, selected variables were analyzed using a univariate linear regression model. Next, variables that were statistically significant, as well as age and sex, were fit into a multiple variable model. The following independent variables were evaluated in the analyses: sociodemographic variables (age, sex, marital status, education, and work status); physical activity; and self-efficacy. Because all bivariate correlations between variables used in the analysis were $r<0.7$, we assumed no multicollinearity of variables. The model fit was assessed by inspection of the residuals. Transformation of the non-normal data was considered, but, since it did not alter the findings and the residuals indicated good model fit, parametric linear regression using untransformed data was determined to be an acceptable statistical approach for analyzing both PCS and MCS scores. The results are presented as estimates of beta with $95 \%$ confidence intervals and $P$-values. The level of 
significance was set at $P<0.05$ and all tests were two-tailed. Cohen's $d$ was used to calculate effect size, and $d \geq 0.4$ was defined as clinically significant. ${ }^{32,33}$ Data were analyzed using SPSS for Windows version 18.0 (IBM Corporation, Armonk, NY, USA).

\section{Results}

\section{Sample characteristics}

The sociodemographic characteristics of the sample are presented in Table 1. Mean age was 64.6 years (standard deviation $=9.5$ ) and ranged from 38 to 85 years. There were no statistically significant demographic differences between the men and women in this sample.

The median scores of the study variables in relation to sex are shown in Table 2. Men scored higher than women on four of the SF-12v2 scales: bodily pain $(P=0.02, d=0.53)$; vitality $(P=0.02, d=46)$; role limitations due to emotional problems $(P=0.004, d=0.57)$; and mental health $(P=0.03$, $d=0.48)$. Men also scored higher on the aggregated mental health component of the SF-12v2 ( $P=0.03, d=0.47)$. No other sex differences were detected.

\section{Regression analyses}

The linear regression analysis included two sets of models, the first predicting physical health (PCS score) and the second predicting mental (MCS score); the model fit for both was very good (Tables 3 and 4). Univariate analyses from the first set showed that only younger age and being in paid work were related to higher PCS ( $P=0.018$ and $P<0.001$, respectively). The other sociodemographic variables, physical activity, and self-efficacy were not related to PCS. The final multivariate model explained $17.6 \%$ of the variance in PCS, and being in paid work was significantly associated with PCS, even when controlling for age and sex.
In the second set of linear regression analyses with MCS as the dependent variable, univariate analyses indicated that being male, living with a partner, having higher levels of physical activity, and having higher self-efficacy were significantly associated with better mental health. Self-efficacy explained $30.0 \%$ of the variance in MCS in the univariate analysis. In the multivariate analysis, living with a partner, having higher physical activity, and having higher selfefficacy were significant predictors of MCS, controlling for age and sex. The final multivariate model explained $40.2 \%$ of the variance in MCS.

\section{Discussion}

The present study indicated that four of the factors examined were significantly associated with HRQoL in adjusted analyses; participation in paid work was associated with higher PCS, while living with a partner, and having higher levels of physical activity, and self-efficacy were associated with higher MCS. Thus, it seems that different factors are related to the physical and mental components of HRQoL. To our knowledge, this is the first study to describe the relationship between general self-efficacy and HRQoL in this population.

\section{Mental health and self-efficacy}

Our findings indicate that self-efficacy is an important factor for mental health, explaining $30 \%$ of the variance in MCS scores. Previous COPD research has found that a higher level of COPD-specific self-efficacy is associated with less anxiety and depression ${ }^{34}$ and better mental health. ${ }^{18}$ The MCS includes items assessing the extent to which emotional symptoms such as anxiety and depression interfered with daily activities. ${ }^{21,22}$ People often experience anxiety when they feel incapable of managing various daily activities, and the inability to accomplish

Table I Sociodemographic characteristics of the study sample

\begin{tabular}{|c|c|c|c|c|c|}
\hline & $\begin{array}{l}\text { All } \\
n=97(100 \%)\end{array}$ & $\begin{array}{l}\text { Men } \\
n=53(54.6 \%)\end{array}$ & $\begin{array}{l}\text { Women } \\
n=44(45.4 \%)\end{array}$ & & $P$-value \\
\hline & Mean (SD) & Mean (SD) & Mean (SD) & $t$ & \\
\hline \multirow[t]{2}{*}{ Age (years): mean (SD) } & $64.6(9.5)$ & $65.1(10.0)$ & $64.0(8.9)$ & 0.584 & $0.56 \mathrm{I}$ \\
\hline & n (\%) & n (\%) & n (\%) & $\chi^{2}(d f)$ & $P$-value \\
\hline Level of formal education & & & & $0.013(1)$ & 0.910 \\
\hline Up to 12 years & $70(72.2)$ & $38(7 \mid .7)$ & $32(72.7)$ & & \\
\hline 13 years or more & $27(27.8)$ & I4 (27.5) & $12(29.3)$ & & \\
\hline Partner status & & & & $2.64 I(I)$ & 0.104 \\
\hline Married/cohabitating & $55(56.7)$ & $34(64.2)$ & $21(47.7)$ & & \\
\hline Employment status & & & & $0.176(1)$ & 0.675 \\
\hline Paid work & $24(24.7)$ & $14(26.4)$ & $10(22.7)$ & & \\
\hline
\end{tabular}

Note: $P$-values reflect comparisons of men and women by Student's $t$-test or chi-square test.

Abbreviations: SD, standard deviation; $d f$, degrees of freedom. 
Table 2 Physical activity, self-efficacy (GSE), and HRQoL (SF-I2v2) scores among men and women

\begin{tabular}{|c|c|c|c|c|c|c|}
\hline \multirow[t]{2}{*}{ Variables } & \multirow[t]{2}{*}{ Scales } & \multirow{2}{*}{$\begin{array}{l}\begin{array}{l}\text { All } \\
\mathrm{n}=97\end{array} \\
\text { Median [IQR] }\end{array}$} & \multirow{2}{*}{$\begin{array}{l}\text { Men } \\
\mathrm{n}=53\end{array}$} & \multirow{2}{*}{$\begin{array}{l}\text { Women } \\
\mathrm{n}=44 \\
\text { Median [IQR] }\end{array}$} & \multirow[t]{2}{*}{$P$-value } & \multirow{2}{*}{$\begin{array}{l}\text { Effect } \\
\text { size } \\
d\end{array}$} \\
\hline & & & & & & \\
\hline Physical activity & $0-3$ & $\mathrm{I} .00[1.50]$ & $1.00[2.00]$ & $1.00[1.00]$ & 0.264 & 0.21 \\
\hline Self-efficacy & $1-40$ & $26.00[11.00]$ & $27.00[10.50]$ & $25.50[10.50]$ & 0.235 & 0.24 \\
\hline \multicolumn{7}{|l|}{ HRQoL scales } \\
\hline Physical functioning & $0-100$ & $25.00[50.00]$ & $25.00[50.00]$ & $25.00[50.00]$ & 0.154 & 0.28 \\
\hline Role physical & $0-100$ & $37.50[37.50]$ & $50.00[50.00]$ & $37.50[46.88]$ & 0.097 & 0.19 \\
\hline Bodily pain & $0-100$ & $75.00[75.00]$ & $75.00[50.00]$ & $50.00[50.00]$ & $0.016^{\mathrm{a}}$ & 0.53 \\
\hline General health & $0-100$ & $25.00[47.50]$ & $25.00[47.50]$ & $25.00[45.00]$ & 0.190 & 0.30 \\
\hline Vitality & $0-100$ & $25.00[50.00]$ & $25.00[25.00]$ & $25.00[25.00]$ & $0.015^{\mathrm{a}}$ & 0.46 \\
\hline Social functioning & $0-100$ & $75.00[75.00]$ & $75.00[62.50]$ & $75.00[68.75]$ & 0.302 & 0.21 \\
\hline Role emotional & $0-100$ & $75.00[62.50]$ & $87.00[37.50]$ & $56.25[62.50]$ & $0.004^{a}$ & 0.57 \\
\hline Mental health & $0-100$ & 62.50 [37.50] & $75.00[37.50]$ & $62.50[25.00]$ & $0.028^{a}$ & 0.48 \\
\hline \multicolumn{7}{|l|}{ HRQoL components } \\
\hline Physical health & $0-100$ & $31.25[16.3]$ & $34.52[17.42]$ & 29.62 [17.19] & 0.156 & 0.29 \\
\hline Mental health & $0-100$ & $45.89[21.5]$ & $53.42[18.51]$ & 43.41 [20.50] & $0.026^{a}$ & 0.47 \\
\hline
\end{tabular}

Notes: Data are study median values and interquartile range. P-values reflect comparisons of men and women by Student's $t$-test (physical activity, GSE) and Mann-Whitney $U$ test (HRQoL scales). Higher HRQoL scores indicate better health. The effect size of each comparison is expressed by Cohen's $d$. HRQoL measured by the short form

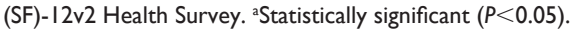

Abbreviations: GSE, General Self-Efficacy Scale; HRQoL, health-related quality of life; IQR, interquartile range.

everyday activities can also contribute to feelings of depression. ${ }^{15}$ Our finding is thus consistent with Bandura's theory ${ }^{15}$ that selfefficacy reflects people's belief in their ability to manage anxiety and depression and to perform daily activities. Consequently, a feeling of control in managing the emotional consequences of the disease, as well as in managing daily activities, might be essential for mental health among patients with COPD. Selfefficacy has been shown to be a mediator of quality of life in many different populations, including those with rheumatoid arthritis, ${ }^{35}$ surgery patients, ${ }^{36}$ and breast cancer survivors. ${ }^{37}$ It is thus likely that self-efficacy is acting as a mediator between disease and mental health in the COPD population as well.

\section{Physical health and self-efficacy}

It is interesting to note that no association was found between general self-efficacy and the PCS, a measure of patients' physical health and the extent to which they are physically capable of performing day-to-day activities. This finding seems to contradict previous studies reporting associations between COPD-specific measures of self-efficacy in relation to physical health. ${ }^{18,19,38}$ However, it has been proposed that self-efficacy could be structured hierarchically from taskspecific to global self-efficacy, ${ }^{39}$ and it is possible that specific and general types of self-efficacy have different associations with physical health in this population. Additional research assessing both task- and context-specific self-efficacy as well as general self-efficacy is warranted to better understand their potentially differing relationships to physical and mental health among patients with COPD.

\section{Physical activity}

The present study indicated no association between selfreported physical activity and the PCS. The low correlation between physical activity and the PCS may seem somewhat

Table 3 Univariate and multivariate linear regression analyses predicting HRQoL physical component summary score ( $\mathrm{n=97)}$

\begin{tabular}{|c|c|c|c|c|c|c|}
\hline \multirow[t]{2}{*}{ Variables } & \multicolumn{3}{|c|}{ Univariate } & \multicolumn{3}{|c|}{ Multivariate } \\
\hline & B & $95 \% \mathrm{Cl}$ & $P$-value & B & $95 \% \mathrm{Cl}$ & $P$-value \\
\hline Age & -0.278 & -0.508 to -0.049 & $0.018^{a}$ & -0.105 & -0.350 to 0.139 & 0.395 \\
\hline Female sex (male as ref) & -3.186 & -7.608 to 1.237 & 0.156 & -2.984 & -7.105 to 1.138 & 0.154 \\
\hline Paid work (no paid work as ref) & 9.913 & 5.168 to 14.659 & $<0.00 \mathrm{I}^{\mathrm{a}}$ & 8.714 & 3.374 to 14.054 & $<0.001^{\mathrm{a}}$ \\
\hline Partnered (unpartnered as ref) & -2.235 & -6.703 to 2.233 & 0.323 & & & \\
\hline Education & -0.068 & -1.675 to 1.538 & 0.933 & & & \\
\hline Physical activity & 2.004 & -0.342 to 4.351 & 0.093 & & & \\
\hline Self-efficacy & 0.299 & -0.036 to 0.635 & 0.080 & & & \\
\hline
\end{tabular}

Note: aStatistically significant $(P<0.05)$.

Abbreviations: $\mathrm{B}$, estimate of beta; $\mathrm{Cl}$, confidence interval; HRQoL, health-related quality of life; ref, reference. 
Table 4 Univariate and multivariate linear regression analyses predicting HRQoL mental component summary score ( $\mathrm{n}=97$ )

\begin{tabular}{|c|c|c|c|c|c|c|}
\hline \multirow[t]{2}{*}{ Variables } & \multicolumn{3}{|c|}{ Univariate } & \multicolumn{3}{|c|}{ Multivariate } \\
\hline & B & $95 \% \mathrm{Cl}$ & $P$-value & B & $95 \% \mathrm{Cl}$ & $P$-value \\
\hline Age & 0.115 & -0.153 to 0.384 & 0.396 & 0.207 & -0.012 to 0.426 & 0.064 \\
\hline Female sex (male as ref) & -5.729 & -10.695 to -0.764 & $0.024^{\mathrm{a}}$ & -2.667 & -6.826 to $|.49|$ & 0.206 \\
\hline Paid work (no paid work as ref) & -2.125 & -7.994 to 3.743 & 0.474 & & & \\
\hline Partnered (unpartnered as ref) & 5.709 & 0.718 to 10.700 & $0.025^{\mathrm{a}}$ & 4.389 & 0.194 to 8.585 & $0.04 I^{\mathrm{a}}$ \\
\hline Education & 1.200 & -0.617 to 3.016 & 0.193 & & & \\
\hline Physical activity & 3.313 & 0.680 to 5.946 & $0.014^{a}$ & 2.737 & 0.473 to 5.000 & $0.018^{\mathrm{a}}$ \\
\hline Self-efficacy & 1.047 & 0.721 to 1.372 & $<0.00 I^{\mathrm{a}}$ & 0.953 & 0.636 to 1.270 & $<0.00 I^{\mathrm{a}}$ \\
\hline
\end{tabular}

Note: a Statistically significant $(P<0.05)$.

Abbreviations: $\mathrm{B}$, estimate of beta; $\mathrm{Cl}$, confidence interval; $\mathrm{HRQ} \mathrm{L}$, health-related quality of life; ref, reference.

surprising, although two systematic reviews also confirm the absence of a clear relationship between physical activity and quality of life in COPD. ${ }^{40,41}$ One potential explanation of these findings is that the PCS provides more in-depth evaluation, covering a variety of aspects of life such as functional status, perceptions, and social opportunities, ${ }^{22}$ ie, not only physical activity. However, higher physical activity was associated with the MCS. This finding is in line with epidemiological studies. ${ }^{42}$ Furthermore, a large multicenter study of COPD patients indicated that the amount of daily walking time was directly related to better HRQoL and inversely related to lower levels of anxiety and depression. ${ }^{13}$

Our course participants, who were just beginning a PR program, reported low levels of leisure time physical activity. Despite the indisputable benefit of physical activity, there are several reasons why persons with COPD find this part of selfmanagement difficult. In addition to the deconditioning cycle, some reasons also lie outside the individual's control, such as variation in their day-to-day condition and exacerbations. ${ }^{8}$ Our participants scored below the general US population norms $^{21}$ on several of the SF-12 scales, such as general health, physical functioning, vitality, and role performance because of physical problems, as well as the PCS and MCS components. Our findings are consistent with similar COPD studies, demonstrating that COPD patients at the start of a PR program tend to report low HRQoL. ${ }^{3,43,44}$ If individuals with COPD, although functionally capable, are not physically active and have low self-efficacy related to physical activity, they may develop a reduced exercise tolerance, become more sedentary, and further compromise their health as they age with the disease. Leisure time physical activity reflects one's own choice, and motivating people to increased physical activity is central in PR. Longitudinal interventional studies have reported a predictive relationship between improvement in exercise tolerance, disease-specific self-efficacy, and quality of life in patients with COPD attending PR. ${ }^{45}$

\section{Paid work}

Our study revealed that being in paid work was associated with better PCS but not with better MCS among patients with COPD. These findings are comparable to the study of Orbon et al, ${ }^{46}$ in which working patients scored higher than patients receiving disability benefits on all quality of life domains of the Chronic Respiratory Questionnaire, ${ }^{47}$ except for the emotions domain. Whether a person is able to remain in paid work is a complex concurrence of many factors, and since working probably demands a reasonably high level of physical health, the causal association between employment status and PCS could function in the reverse direction, with not having a paid job being primarily a consequence of being severely affected with COPD and having poor HRQoL. If so, disease severity could act as a potential confounder of the relationship between employment status and HRQoL. However, previous studies show divergent results regarding the importance of disease severity for work status. ${ }^{46,48}$ The positive association between paid work and the PCS might cautiously be interpreted to suggest that keeping COPD patients at work would have a positive impact on their physical health. Because of persistent symptoms of breathlessness, persons with COPD tend to adopt a sedentary life style, which reduces their physical condition in a downward spiral, referred to as the "COPD vicious cycle". ${ }^{8,49}$ Paid work may help persons to keep up with daily routines and require them to be at least somewhat physically active, thereby delaying this cycle. Thus, these results might also suggest the possibility that promoting work-related rehabilitation for those with work capacity could be beneficial for maintaining or improving quality of life among subjects with COPD. Kremer et al ${ }^{50}$ pointed out in their study that, in order to influence participation in paid work in this population, more attention should be paid to work place adjustments. Therefore, interventions for COPD patients who are still working should be designed and evaluated in future research. 


\section{Partnership}

Living with a partner was related to higher MCS scores in the present study, in accordance with studies showing that marital satisfaction is a strong predictor of life satisfaction and well-being. ${ }^{51}$ In PR, patients with poor attendance have been found to have less social support. ${ }^{52}$ On the other hand, a study by Bratås et $a l^{53}$ yielded interesting insights regarding the role of next of kin and PR, showing that patients living alone are more likely to achieve or improve their HRQoL 6 months after rehabilitation compared to patients living with someone. Although living alone might require greater self-care and self-responsibility, the above study recommends involving a spouse or partner in PR in order to improve the maintenance of its positive effects. ${ }^{53}$

\section{Sex differences}

Women had lower scores than men on several HRQoL scales and on the MCS. Other studies also report lower MCS scores in women than men with COPD and severe emphysema, ${ }^{54-57}$ and a Dutch population-based study also demonstrated lower PCS scores among women compared to men..$^{58}$ These findings underscore the necessity for more studies of sex differences in order to tailor the provision of health care services to the potentially differing needs of men and women and thereby achieve comparable health outcomes.

\section{Representativity of the sample}

The selection of patients in the present sample is not random, but does represent many rehabilitation centers in Southern Norway. The inclusion rate is high (76\%), and comparison of study participants and non-participants indicates no differences in relation to age or the proportions of men and women. In Norway, patients are generally referred to PR by their general practitioner or by a lung specialist, and the public health system covers the expenses. However, no standard written criteria for referral exists. Guidelines from the Global Initiative for Chronic Obstructive Lung Disease (GOLD) emphasize referral at an early stage of the disease to promote earlier use of preventive strategies. ${ }^{8}$ Criteria based on lung function parameters alone is not recommended in patient selection, since forced expiratory volume in $1 \mathrm{sec}-$ ond $\left(\mathrm{FEV}_{1}\right)$ is a relatively poor correlate of symptoms such as breathlessness and the impact of COPD on daily life. ${ }^{59}$ Selection could also be based on functional limitations due to respiratory symptoms, potential for improvement, and motivation to participate actively. ${ }^{60}$ Although more information is needed on criteria for patient selection for PR, all COPD patients appear to benefit. ${ }^{8}$ From clinical experience, we know that the distribution of disease severity and other relevant characteristics shows wide variations in patients attending such courses. Our sample probably reflects the heterogeneity in a natural setting of patients attending $\mathrm{PR}$, and should therefore be representative, allowing generalizations about Norwegian patients enrolled in PR. As a result, this study provides important insights into some of the factors that are associated with the physical and mental components of HRQoL in this population.

\section{Study limitations}

This study has some limitations. First is the lack of available data regarding disease severity, performance-based physical activity, and other clinical variables (eg, body mass index, smoking history, and comorbid conditions), as these factors may influence the relationships observed in this study. However, previous research has demonstrated low ${ }^{61}$ to moderate ${ }^{5}$ correlation between HRQoL, as measured with the SF-36, and disease severity among COPD patients. Another study limitation is that the cross-sectional design prevents interpretations of causality, and additional longitudinal studies are warranted to determine the nature of relationships between general self-efficacy and HRQoL over time in this population. Since our study relied on self-reported data, another limitation is that the participants' answers may have been influenced by their wish to either exaggerate or minimize the effect of their disease on issues such as levels of physical activity. This possible threat to validity should be common for all participants, but the study would have been strengthened by the inclusion of objective measures.

\section{Conclusion}

The present study suggests that physical activity, general self-efficacy, participation in paid work, and partnership might be important factors for improving the HRQoL of persons with COPD and should be taken into consideration in pulmonary rehabilitation. These factors might also play a role in reducing the attrition of benefits commonly observed after patients leave $\mathrm{PR},{ }^{19,62}$ but further research is needed to clarify such relationships. Nonetheless, to maintain patients HRQoL, individualized needs assessments are recommended, with particular emphasis on their self-care abilities and factors such as physical activity, paid work, social relationships, and self-efficacy. ${ }^{63}$

\section{Acknowledgments}

RA acknowledges the financial support she received from the Research Foundation of the Norwegian Heart and Lung 
Patient Organization (LHL). The study was funded by the Norwegian Centre for Patient Education, Research and Service Development, Oslo, Norway.

\section{Author contributions}

RA contributed to the conception and design of the study as well as the analysis and interpretation of the data, and also drafted the manuscript. SBB contributed to analysis and interpretation of data, and to critical revision of the manuscript for intellectual content. KH contributed to the conception and design of the study, acquisition of data and to revision of the manuscript. MSF was the main contributor to the conception and design of the study, acquisition of the data, and critical revision of the manuscript. AL contributed to the conception and design of the study, drafted parts of the manuscript, performed statistical analyses, and critically revised the manuscript. All authors read and approved the final manuscript.

\section{Disclosure}

The authors report no conflicts of interest in this work.

\section{References}

1. Burden of COPD [webpage on the Internet]. Geneva: World Health Organization [cited October 28, 2013]. Available from: http://www. who.int/respiratory/copd/burden/en/. Accessed March 19, 2014.

2. Biskobing DM. COPD and osteoporosis. Chest. 2002;121:609-620.

3. van Manen JG, Bindels PJ, Dekker FW, et al. The influence of COPD on health-related quality of life independent of the influence of comorbidity. J Clin Epidemiol. 2003;56(12):1177-1184.

4. Bentsen SB, Henriksen AH, Wentzel-Larsen T, Hanestad BR, Wahl AK. What determines subjective health status in patients with chronic obstructive pulmonary disease: importance of symptoms in subjective health status of COPD patients. Health Qual Life Outcomes. 2008;6:115

5. Ståhl E, Lindberg A, Jansson SA, et al. Health-related quality of life is related to COPD disease severity. Health Qual Life Outcomes. 2005;3:56

6. Fayers PM, Machin D. Quality of Life: the Assessment, Analysis and Interpretation of Patient-Reported Outcomes. Chichester: John Wiley; 2007.

7. Moons P, Budts W, De Geest S. Critique on the conceptualisation of quality of life: a review and evaluation of different conceptual approaches. Int J Nurs Stud. 2006;43(7):891-901.

8. GOLD. Global strategy for the diagnosis, management, and prevention of Chronic Obstructive Pulmonary Disease. Global Initiative for Chronic Obstructive Lung Disease (GOLD) [serial online] 2014;i-30 [updated Jan 2014; cited October 28, 2013]. Available from: http:// www.goldcopd.org/uploads/users/files/GOLD_Report2014_Feb07.pdf. Accessed March 19, 2014.

9. Nici L, Donner C, Wouters E, et al. American Thoracic Society/European Respiratory Society statement on pulmonary rehabilitation. Am J Respir Crit Care Med. 2006;173(12):1390-1413.

10. Ries AL, Bauldoff GS, Carlin BW, et al. Pulmonary Rehabilitation: joint ACCP/AACVPR evidence-based clinical practice guidelines. Chest. 2007;131(Suppl 5):4S-42S.

11. Cazzola M, Donner CF, Hanania NA. One hundred years of chronic obstructive pulmonary disease (COPD). Respir Med. 2007;101(6): 1049-1065.
12. Garcia-Aymerich J, Lange P, Benet M, Schnohr P, Anto JM. Regular physical activity reduces hospital admission and mortality in chronic obstructive pulmonary disease: a population based cohort study. Thorax. 2006;61(9):772-778.

13. Miravitlles M, Cantoni J, Naberan K. Factors associated with a low level of physical activity in patients with chronic obstructive pulmonary disease. Lung. 2014;192:259-265.

14. Barlow J, Wright C, Sheasby J, Turner A, Hainsworth J. Self-management approaches for people with chronic conditions: a review. Patient Educ Couns. 2002;48:177-187.

15. Bandura A. Self-Efficacy: the Exercise of Control. New York: Freeman; 1997.

16. Bourbeau J, Nault D, Dang-Tan T. Self-management and behaviour modification in COPD. Patient Educ Couns. 2004;52(3):271-277.

17. Kara M, Asti T. Effect of education on self-efficacy of Turkish patients with chronic obstructive pulmonary disease. Patient Educ Couns. 2004;55(1):114-120.

18. Arnold R, Ranchor AV, Koeter GH, et al. Changes in personal control as a predictor of quality of life after pulmonary rehabilitation. Patient Educ Couns. 2006;61(1):99-108.

19. Bentsen SB, Wentzel-Larsen T, Henriksen AH, Rokne B, Wahl AK. Self-efficacy as a predictor of improvement in health status and overall quality of life in pulmonary rehabilitation - an exploratory study. Patient Educ Couns. 2010;81(1):5-13.

20. Lerdal A, Andenæs R, Bjørnsborg E, et al. Personal factors associated with health-related quality of life in persons with morbid obesity on treatment waiting lists in Norway. Qual Life Res. 2011;20(8): $1187-1196$

21. Ware JE, Kosinski M, Turner-Bowker DM, Gandek B. How to score version 2 of the $S F-12^{\circledR}$ Health Survey (with a supplement documenting version 1). Lincolm, RI: QualityMetric Inc.; 2005.

22. Ware J Jr, Kosinski M, Keller SD. A 12-Item Short-Form Health Survey: construction of scales and preliminary tests of reliability and validity. Med Care. 1996;34(3):220-233.

23. Gandek B, Ware JE, Aaronson NK, et al. Cross-validation of item selection and scoring for the SF-12 Health Survey in nine countries: results from the IQOLA Project. International Quality of Life Assessment. J Clin Epidemiol. 1998;51:1171-1178.

24. Katz PP, Eisner MD, Yelin EH, et al. Functioning and psychological status among individuals with COPD. Qual Life Res. 2005;14(8): $1835-1843$.

25. Drøyvold WB, Holmen J, Midthjell K, Lydersen S. BMI change and leisure time physical activity (LTPA): an 11-y follow-up study in apparently healthy men aged 20-69 y with normal weight at baseline. Int J Obes Relat Metab Disord. 2004;28(3):410-417.

26. Kurtze N, Rangul V, Hustvedt BE, Flanders WD. Reliability and validity of self-reported physical activity in the Nord-Trøndelag Health Study: HUNT 1. Scand J Public Health. 2008;36(1):52-61.

27. Moe B, Augestad LB, Nilsen TIL. Diabetes severity and the role of leisure time physical exercise on cardiovascular mortality: the Nord-Trøndelag Health study (HUNT), Norway. Cardiovasc Diabetol. 2013;12:83.

28. Schwarzer R. Self-Efficacy Research; Research Publications on Perceived Self-Efficacy [homepage on the Internet]. Berlin: Freie Universität Berlin [Updated January 22, 2013; cited October 15, 2013]. Available from: http://www.ralfschwarzer.de. Accessed March 19, 2014.

29. Schwarzer R, Jerusalem M. Generalized self-efficacy scale. In: Weinman S, Wright S, Johnston M, editors. Measures in Health Psychology: a User's Portfolio. Winsor, UK: Nfer-Nelson; 1995:35-37.

30. Leganger A, Kraft P, Roysamb E. Perceived self-efficacy in health behaviour research: conceptualisation, measurement and correlates. Psychology and Health. 2000;15(1):51-69.

31. Cronbach LJ. Essentials of Psychological Testing. New York: Harper and Row; 1990.

32. Cohen J. Statistical Power Analysis for the Behavioural Sciences. 2nd ed. Hillsdale: Lawrence Earlbaum Associates; 1988. 
33. Cohen J. A power primer. Psychol Bull. 1992;112(1):155-159.

34. Bentsen SB, Wentzel-Larsen T, Henriksen AH, Rokne B, Wahl AK. Anxiety and depression following pulmonary rehabilitation. Scand $J$ Caring Sci. 2013;27(3):541-50.

35. Knittle K, De Gucht V, Hurkmans E, et al. Effect of self-efficacy and physical activity goal achievement on arthritis pain and quality of life in patients with rheumatoid arthritis. Arthritis Care Res. 2011;63(11): 1613-1619.

36. Abbott AD, Tyni-Lenné R, Hedlund R. The influence of psychological factors on pre-operative levels of pain intensity, disability and health-related quality of life in lumbar spinal fusion surgery patients. Physiotherapy. 2010;96(3):213-221.

37. Sherman KA, Heard G, Cavanagh KL. Psychological effects and mediators of a group multi-component program for breast cancer survivors. J Behav Med. 2010;33(5):378-391.

38. Garrod R, Marshall J, Barley E, Jones PW. Predictors of success and failure in pulmonary rehabilitation. Eur Resp J. 2006;27(4):788-794.

39. Choi N. Sex role group differences in specific, academic, and general self-efficacy. J Psychol. 2004;138(2):149-159.

40. Bossenbroek L, de Greef MH, Wempe JB, Krijnen WP, ten Hacken NH. Daily physical activity in patients with chronic obstructive pulmonary disease: a systematic review. COPD. 2011;8(4):306-319.

41. Chavannes N, Vollenberg JJ, van Schayck CP, Wouters EF. Effects of physical activity in mild to moderate COPD: a systematic review. Br J Gen Pract. 2002;52(480):574-578.

42. Bertheussen GF, Romundstad PR, Landmark T, Kaasa S, Dale O, Helbostad JL. Associations between physical activity and physical and mental health - a HUNT 3 study. Med Sci Sports Exerc. 2011;43(7): $1220-1228$.

43. Katsura H, Yamada K, Kida K. Both generic and disease specific healthrelated quality of life are deteriorated in patients with underweight COPD. Respir Med. 2005;99(5):624-630.

44. Griffiths TL, Burr ML, Campbell IA, et al. Results at 1 year of outpatient multidisciplinary pulmonary rehabilitation: a randomised controlled trial. Lancet. 2000;355(9201):362-368.

45. Lox CL, Freehill AJ. Impact of pulmonary rehabilitation on selfefficacy, quality of life, and exercise tolerance. Rehabil Psychol. 1999;44(2):208-221.

46. Orbon KH, Schermer TR, van der Gulden JW, et al. Employment status and quality of life in patients with chronic obstructive pulmonary disease. Int Arch Occup Environ Health. 2005;78(6):467-474.

47. Guyatt GH, Berman LB, Townsend M, Pugsley SO, Chambers LW. A measure of quality of life for clinical trials in chronic lung disease. Thorax. 1987;42(10):773-778.

48. Sin DD, Stafinski T, Ng YC, Bell NR, Jacobs P. The impact of chronic obstructive pulmonary disease on work loss in the United States. Am J Respir Crit Care Med. 2002;165(5):704-707.
49. Braido F, Baiardini I, Menoni S, et al. Disability in COPD and its relationship to clinical and patient-reported outcomes. Curr Med Res Opin. 2011;27(5):981-986.

50. Kremer AM, Pal TM, van Keimpema AR. Employment and disability for work in patients with COPD: a cross-sectional study among Dutch patients. Int Arch Occup Environ Health. 2006;80(1):78-86.

51. Fincham FD, Beach SR. Marriage in the new millennium: a decade in review. Journal of Marriage and Family. 2010;72(3):630-649.

52. Troosters T, Gosselink R, Janssens W, Decramer M. Exercise training and pulmonary rehabilitation: new insights and remaining challenges. Eur Respir Rev. 2010;19(115):24-29.

53. Bratås O, Espnes G, Rannestad T, Walstad R. Relapse of health related quality of life and psychological health in patients with chronic obstructive pulmonary disease 6 months after rehabilitation. Scand $J$ Car Sci. 2012;26(2):219-227.

54. Tam A, Morrish D, Wadsworth S, Dorscheid D, Man SF, Sin DD. The role of female hormones on lung function in chronic lung diseases. $B M C$ Womens Health. 2011;11:24.

55. Carrasco Garrido P, de Miguel-Diez J, Rejas-Gutierrez J, et al. Characteristics of chronic obstructive pulmonary disease in Spain from a gender perspective. BMC Pulm Med. 2009;9:2-8.

56. Martin A, Rodriguez-González Moro JM, Izquierdo JL, Gobartt E, de Lucas P; VICE Study Group. Health-related quality of life in outpatients with COPD in daily practice: the VICE Spanish Study. Int J Chron Obstruct Pulmon Dis. 2008;3(4):683-692.

57. Martinez FJ, Curtis JL, Sciurba F, et al. Sex differences in severe pulmonary emphysema. Am J Respir Crit Care Med. 2007;176(3): 243-252.

58. Mols F, Pelle AJ, Kupper N. Normative data of the SF-12 health survey with validation using postmyocardial infarction patients in the Dutch population. Qual Life Res. 2009;18(4):403-414.

59. Jones P, Miravitlles M, van der Molen T, Kulich K. Beyond FEV1 in COPD: a review of patient-reported outcomes and their measurement Int J Chron Obstruct Pulmon Dis. 2012;7:697-709.

60. Ries AL, Desai S. Rehabilitation. In: Voelkel NF, MacNee W, editors. Chronic Obstructive Lung Disease. 2nd ed. Hamilton: BC Decker Inc.; 2008:421-429.

61. Pickard AS, Yang Y, Lee TA. Comparison of health-related quality of life measures in chronic obstructive pulmonary disease. Health Qual Life Outcomes. 2011;9:26.

62. Bentsen S, Langeland E, Holm A. Evaluation of self-management interventions for chronic obstructive pulmonary disease. J Nurs Manag. 2012;20(6):802-813.

63. Richard AA, Shea K. Delineation of self-care and associated concepts. J Nurs Scholarsh. 2011;43(3):255-264.
Journal of Multidisciplinary Healthcare

\section{Publish your work in this journal}

The Journal of Multidisciplinary Healthcare is an international, peerreviewed open-access journal that aims to represent and publish research in healthcare areas delivered by practitioners of different disciplines. This includes studies and reviews conducted by multidisciplinary teams as well as research which evaluates the results or conduct of such teams or

\section{Dovepress}

healthcare processes in general. The journal covers a wide range of areas and welcomes submission from practitioners at all levels, from all over the world. The manuscript management system is completely online and includes a very quick and fair peer-review system. Visit http://www.dovepress.com/testimonials.php to read real quotes from published authors. 